The Secretary General in his opening report referred to the Pathological Museum as one of the chief educational works of the Congress, and there can be little doubt that no such collection of tuberculous specimens has ever before been brought together. Every known tuberculous lesion in man and in the lower animals is illustrated, and every bacillus that in the smallest degree resembles the tubercle bacillus is represented. Classical specimens of Potts, Addison and Astley Cooper are all shown, and of specimens of later date a really typical collection has been made. After other features in the history of the Congress had been alluded to by the Secretary General, the Congress was declared open and a telegram was sent to the King. An answer to this telegram, wishing the Congress all success, came before the close of the meeting. The delegates were then addressed by the Marquis of Lansdowne, Earl Cadogan, the Lord Mayor of London, Lord Strathcona and Lord Lister, whose remarks are reported by the Times as follows :-

He said they met under immeasurably happier auspices than could possibly have been the case not many years ago. Thanks to the labours of the illustrious man who would address the general meeting on the following day, they now knew the enemy they had to deal with, which before the discovery of the tubercle bacillus was shrouded in impenetrable obscurity. They also knew, thanks to Pasteur, that that microbe was incapable of originating de nozio in the human body; that, while some constitutions were more prone to its invasion than others, it must always be derived from similar organisms in the external world. Hence there came to be opened up the splendid prospect of the prevention of tuberculosis. But it was by no means only prevention that they were looking at. They also aimed in the present day at the cure of consumption. In this respect matters were very much more hopeful than they had been till quite recently. The physician might learn a great deal in this point of view from the experiences of the surgeon. There were a great many surgical complaints which they now knew to be just as much tubercular as pulmonary consumption - that was to say, they were just as much due to the growth of the tubercle bacillus. Yet the surgeon knew that in many of these cases the disease might be completely cured that, in consequence of the means - of which they were getting to know more and more every day - which the animal organism had of resisting microscopic invaders, the tubercle bacillus was not only arrested in its progress, but swept away altogether, and the result came to be a healthy state of the tissues and parts in which it was. These experiences showed that tuberculosis was not necessarily an incurable disease. That was an immense point to have demonstrated. Thus, they were not surprised to learn that physicians were coming to look upon the cure of consumption more hopefully than they used to do, by treating it on recognised principles and on the same broad, general lines as surgical tuberculosis. For his own part, as a surgeon, he had had cases of pulmonary disease brought but little under his notice; but he had been surprised, even in his limited experience, at the numerous cases among his own patients in which people who many years ago had consumptive lungs had subsequently become free from all traces of the disease and had lived healthy, robust and useful lives. These cases he ventured humbly to regard as cases of cure of consumption. Then there were attempts now being made by the use of various specific means to deal with consumption even in its more advanced forms. He must not refer to that at the present time further than to say that some of them at least had very promising aspects. They might be sure that these means would be most carefully considered by the Congress, and he need not say how cordially he hoped and anticipated that their deliberations would be fraught with good. There was another point in which he believed the Congress would be useful besides the concentrated wisdom of the eminent men who had come as delegates to take part in it. If the prevention of tuberculosis was to be effectively carried out, the general public must aid the physician and the surgeon in the endeavour. He anticipated that that spiendid gathering of scientific men from all parts of the world, meeting under Royal patronage, for which he might venture to express their profound gratitude, would indicate to he public the vast importance of the work they were engaged in and would lead to their cooperation in the endeavour to minimise and possibly eventually to stamp out entirely the greatest scourge of the human race.

Some idea of the standing of the delegates may be gathered from the following list of those who were presented to H.R.H. the Duke of Cambridge, and who spoke, each on behalf of his nation :-Prof. Osler, from the United States of America: Prof. von Schrötter, Austria; M. le Senateur Montefiore Levi, Belgium; Prof. Charles Gram, Denmark ; Prof. Brouardel, France; Prof. von Leyden, Germany ; Prof. Thomassen, Holland; Prof. Frédéric Koranyi, Hungary; Sua Eccellenza Senator Enrico di Rienzi, Italy; Prof. Holmboë, Norway ; Prof. Cortezo, Spain; Prof. Hofmarshal Printzsjöld, Sweden : Dr. Louis Secretan, Switzerland. Greece and Roumania were also represented, as well as the Universities and all the medical societies and public health bodies in the kingdom.

The work of the Congress has been arranged in four sections. In the first all questions concerning the relations of the State and municipalities to the prevention of tuberculosis are to be discussed, and if the number of papers announced is any criterion, little should remain undiscussed at the conclusion of the Congress. The second section deals with medicine, including climatology; the third with pathology, including bacterio$\operatorname{logy} ;$ and the fourth with tuberculosis in animals.

In addition to the purely sectional work, three general addresses will be given. The first of these, by Prof. Koch, of Berlin, dealing with the preventive measures to be taken in connection with tuberculosis, is printed in full in this number; Prof. Brouardel, of Paris, will give the second address : and Prof. McFadyean, of the Royal Veterinary College, the third. Prof. Koch is also announced to open a discussion on tuberculin-a discussion that should be of a very interesting character.

The "social" programme is unusually attractive, but in no way interferes with the efficient working of the important or business meetings of the Congress. We shall watch with interest the further proceedings of the Congress.

\section{THE LIQUEFACTION OF HYDROGEN.}

$\mathrm{THE}$ liquefaction and solidification of hydrogen form the last of the definite stages, so far, in the progress towards the absolute zero of temperature. To make the account of this stage clear, it will be necessary to compare it briefly with those which preceded it.

During the third decade of the last century, Faraday found that, whereas different substances have different boiling-temperatures at ordinary pressure, or different condensation-pressures at ordinary temperature, the lowest boiling point could be lowered further by reducing the pressure artificially. Thus by exhausting with a vacuum-pump the vapour from a vessel containing solid carbonic acid, he was able to obtain cold intense enough to liquefy a large number of gases exposed to the low temperature and, at the same time, to considerable pressure. This may be called the vaporisation method of cooling. Pictet in $x 877$ showed how its effect might be intensified by using the cold so obtained by the low-pressure boiling of one substance, such as sulphur dioxide, to condense at high pressure some more volatile gas, such as carbonic acid, the subsequent boiling of which at reduced pressure would produce a further reduction of temperature. The successive falls of temperature obtained in this way have caused this to be known as the cascade system of refrigeration. Pictet himself thought that by this means he succeeded in liquefying and solidifying hydrogen, and, though this was probably a mistake, the method has proved a very useful one. By the choice of more suitable substances, carbonic acid and ethylene, NO. I 656, VOL. 64] 
Wróblewski and Olszewski in 1883 succeeded for the first time in cooling oxygen or air to such a low temperature that under moderate pressure it condensed and remained as a visible liquid, of which, when it was allowed to boil at ordinary pressure, a portion remained liquid at a lower temperature. This cascaded vaporisation method, the direct descendant of Faraday's system, was subsequently used by Dewar in improved apparatus on a larger scale, and was the only means of obtaining considerable quantities of liquid air down to 1895 . Attempts were made by others than Pictet to apply it to the liquefaction of hydrogen. But the critical temperature of hydrogen, above which no pressure can liquefy it, is so low that even air boiling into a vacuum at, say, $-210^{\circ} \mathrm{C}$, or solid nitrogen at $-225^{\circ} \mathrm{C}$., is not cold enough to cool it below its critical point. If an intermediate gas could have been found, with a critical point high enough to admit of its being condensed under high pressure at the lowest temperature of liquid air, and boiling under reduced pressure at a temperature below the critical point of hydrogen, the problem would have been solved. Nature having provided no such gas, Dewar tried to make one by mixing nitrogen and hydrogen, in the hope that, after the manner of oxygen and nitrogen in air, they would liquefy together. Olszewski made a similar attempt with a mixture of oxygen and hydrogen; but no one succeeded in liquefying hydrogen by the employ. ment of vaporisation cooling, though intensified by cascading in four stages.

Meantime, another method of obtaining a cooling effect had been employed. Thomson and Rankine had shown theoretically in 1852 , and Giffard practically in 1873 , that if compressed gas be allowed to expand in a cylinder doing work against a piston, the work done externally is represented by a corresponding diminution of the heat-energy of the gas. Similarly, if an iron vessel containing highly compressed gas have the valve opened, the contained gas is forcibly driven out against the resistance due to the generation of a very high velocity. The work of driving it out against this resistance is at any moment being done by the expansion of that which remains inside the vessel, and this remaining gas is cooler in virtue of the work so done. This is the cooling of a gas by work-expansion. In I 877 Cailletet made use of this method to give the first definite practical proof that it was possible to liquefy oxygen, then known as a permanent gas. The vessel in which he had it enclosed under high pressure was a strong glass tube of small bore, which was surrounded by liquid sulphur dioxide or nitrous oxide to give the compressed oxygen a preliminary cooling. The opening of a water-valve then allowed the gas to do the work of driving some water forcibly through, and the gas, after this work-expansion, was so much colder that part of it was condensed into a visible, though evanescent, mist or vapour of oxygen. In 1884 Wróblewski and Olszewski applied the same method to hydrogen, using for preliminary cooling the lowest temperature of liquid air under reduced pressure, and obtained a similar result. Thus a combination of cooling by work-expansion with preliminary cooling by cascaded vaporisation succeeded in practically proving that hydrogen could be liquefied, though it was not possible by any such combination to keep, examine and work with liquid hydrogen.

But there is a third method of cooling a gas-that of free expansion. In the case of the iron vessel containing compressed gas, that gas which is at any moment expanding from the valve is found to be colder immediately after expansion than it was immediately before, though it has, in the act of expansion, done no tangible external work such as it does when expanding within the vessel or behind a piston. It has, however, displaced atmospheric air, given itself considerable residual momentum, and overcome the forces of intermolecular and intramolecular attraction. In virtue of this work done, it has undergone some cooling, the cooling of free expansion. This cooling from free expansion is much less for a given change of pressure than that from work-expansion, or that from vaporisation; so much so that Thomson and Joule had proposed no use for it, and great practical authorities, Siemens and Coleman, had declared that nothing could be accomplished by it - a judgment apparently confirmed by the abortive result of Piazzi Smyth's persevering efforts to utilise it. It is obvious, however, that if there were a method of refrigeration in which the cooling could be continually intensified by accumulation, this method would have a great advantage and would lead ultimately to lower temperatures than other methods which had the benefit of greater initial cooling. This proved to be the case with the method of free expansion. In I 894 Hampson proposed to intensify continually the cooling on this method by accumulating in the compressed gas to be expanded all, or nearly all, of the refrigeration produced by the free expansion of previous portions. This was to be done by letting the compressed gas expand through a nozzle or valve from one end of a long tube and making all the gas, when expanded, immediately return over the tube which it had previously traversed as compressed gas towards the expansion-valve. In the course of this return it cools the succeeding portions of compressed gas which are flowing past it inside the tube, so that as they pass to the expansion point they contain all the cooling which has been previously effected. Thus the compressed gas is continually expanding from a lower temperature than before, and is consequeutly reaching, with the added expansion-cooling, a lower temperature than had been reached by previous portions of expanded gas. This intensification goes on until the cooling is great enough to liquefy a small portion of the expanding gas. The losses in this system are due to imperfect interchange of temperature between the compressed and the expanded gas and to the penetration of external heat, so that its performance depends on the efficiency and compactness of the interchanger or countercurrent accumulator. This method of obtaining intense refrigeration involves the combination of free expansion of gas (not liquid) with intensification by counter-current interchange. Hampson constructed and worked his apparatus in 1896, and in its present form it begins liquefying air in less than ten minutes without employing auxiliary refrigerants. A process involving substantially the same combination was invented at or near the same time by Linde, who, in 1895 , succeeded in liquefying air with it in fifteen hours. His form of apparatus has since liquefied air in two hours, but requires auxiliary refrigeration in the form of ice and salt or a subsidiary ammonia machine.

The special advantage of the Hampson or Linde method for the liquefaction of hydrogen is that it can take gas at an initial temperature from two to three times as high as its critical temperature, and cool it progressively to the point at which it condenses continuously, without the assistance of any substance boiling below its critical temperature - a condition which had been the stumbling-block of the methods employed by Wróblewski, Olszewski and Dewar. With such an appliance available it would seem that the last difficulty in the way of liquefying hydrogen had been removed. Joule and Thomson, however, had observed that hydrogen, on free expansion, instead of being cooled, is actually heated a little. But they had also observed facts which showed how this difficulty could be overcome. The amount of cooling on free expansion varies with the expansiontemperature and with the nature of the gas. Firstly, as to temperature. The lower the initial temperature the greater the cooling for a given degree of expansion, the variation being inversely proportional to the square of the temperature on the absolute scale. Thus, for every

NO. I656, VOL. 64] 
atmosphere that the pressure falls in expansion, air at normal temperature is cooled about a quarter of a degree Centigrade. But expanding from three-quarters of that temperature, or $-56^{\circ} \mathrm{C}$., it is cooled nearly twice as much, or half a degree, for each atmosphere that the pressure falls. And Thomson considered that, if allowed to expand from an initial temperature of $100^{\circ} \mathrm{C}$., it would undergo no cooling at all. The differences of cooling for different substances point in the same direction. Joule and Thomson found that gases which are at a lower point in the scale of corresponding states show more cooling on free expansion than others. Thus oxygen, which is not so far above its critical point as nitrogen, shows more cooling; and carbonic acid, which is actually below its critical point, shows much more. It was a reasonable conclusion then that hydrogen also, if it were made a much less perfect gas by being cooled down to a temperature not much above its critical point, would undergo considerable cooling on free expansion. Early in 1896 Onnes calculated that if hydrogen were cooled to $-210^{\circ} \mathrm{C}$. before free expansion it would be in the same position in the scale of corresponding states as oxygen expanding from $-20^{\circ} \mathrm{C}$. Now oxygen expanding from $-20^{\circ}$ is in a very favourable condition for cooling on free expansion, for it can be liquefied by that method from an initial temperature of $+30^{\circ}$ C., and hydrogen can readily be cooled below $-200^{\circ} \mathrm{C}$. by air boiling at low pressure.

In 1898 Dewar had an apparatus constructed to work on the principle above described, and succeeded in collecting hydrogen as a stable liquid, thus obtaining temperature which he subsequently estimated by platinum-resistance thermometer at $-2384^{\circ} \mathrm{C}$, or $34^{\circ} 6^{\circ} \mathrm{A}$, by constant volume hydrogen thermometer at $-253^{\circ} \mathrm{C}$, or $20^{\circ} \mathrm{A}$. Later, he boiled liquid hydrogen at low pressure and found it to be, like nitrogen and carbonic acid, one of the substances which readily freeze themselves by evaporation. In the solid hydrogen thus obtained he reached the lowest temperature known, which he estimated at from $13^{\circ}$ to $15^{\circ} \mathrm{A}$--temperatures confirmed by his subsequent observations by helium thermometer.

Liquid hydrogen has already been turned to useful account in scientific work by Ramsay and Travers in their researches on the rare inactive gases of the atmosphere. For the purpose of obtaining pure neon by a process of fractional distillation, it was necessary to have so low a temperature that liquid hydrogen had to be employed as a cooling agent. To make this, Travers designed an apparatus on the plan described above, to work in combination with a Hampson air-liquefier which they had at their disposal. The plan involved the preliminary cooling of hydrogen by liquid air at low pressure and its further cooling by free expansion with intensification by counter-current interchange. The Dewar form of the apparatus appears, from such descriptions of it as have been published, to be on the same general plan. The Travers apparatus is fully described, with a drawing to scale, in a paper by its designer in the Philosophical Magazine for April I90I. For the present purpose a clearer idea of its working will be obtained from a simplified diagram of it, such as is here given. To avoid complexity, the insulation, the joints and many other details have been omitted.

The operation is as follows: hydrogen is compressed in a pump, the plungers of which are lubricated with water, to a pressure of about 200 atmospheres. The lubrication water and any hydrogen dissolved in it or blown off with it pass together from the water-separator by the tube $\mathrm{T}$ for further separation at low pressure in a chamber guarded by a water-seal, whence the gas returns by $U$ and $O$ to the gas-holder. The high-pressure gas from the compressor and a drying purifier passes by the tube A through a coil in the vessel $\mathrm{B}$, containing solid carbonic acid in methylated spirit, by which the hydrogen is cooled to $-79^{\circ} \mathrm{C}$. Thence it passes through the coil $\mathrm{C}$ in another vessel containing liquid air, and the temperature is thereby reduced to about $-185^{\circ} \mathrm{C}$. In the next vessel lower it is reduced, in the coil D, to a temperature below $-200^{\circ} \mathrm{C}$. by liquid air boiling at reduced pressure. The liquid air for this purpose is admitted, as required, by the valve $E$ from the vessel above; and the low pressure is maintained in the vessel $D$ by an exhaust-pump connected with it by the tube $\mathrm{F}$ and the passage R S. The compressed hydrogen at the temperature of low-pressure liquid air then passes through the coil $K$ in the vessel $P$, forming the counter-current interchanger, and so reaches the expansion-valve $\mathrm{xr}$. It is in this lowest vessel that the operation takes place which has made the liquefaction of hydrogen possible. The vessel and coil $\mathrm{K}$ have been previously reduced to the temperature of low-pressure air in the following way. The vessel is connected with the exhaust-pump through the annular passage $\mathrm{L}$ and the tube $\mathrm{F}$ by opening the tap $\mathrm{G}$ and closing $\mathrm{H}$. The tap $\mathrm{Q}$ at the bottom of the vessel having

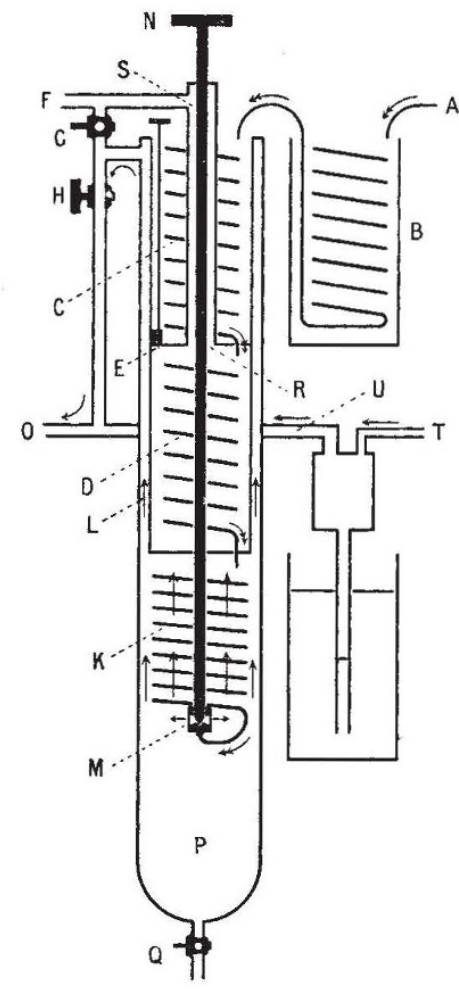

FIG. I.-A, from compressor $\longrightarrow$ high-pressure gas; $M$, expansion.valve $\longrightarrow$, low-pressure gas ; o, to gas-hold:r ; F, to exhaust-pump ; T, from water-separator of compressor.

been opened, a supply of liquid air is drawn up into the vessel by the suction of the exhaust-pump; and the tap being then closed, the exhaust pressure causes the liquid air to boil at a reduced temperature, cooling the vessel $\mathrm{P}$, the coil $\mathrm{K}$, and the compressed hydrogen within it to about $-205^{\circ} \mathrm{C}$. The vessel is now cut off from the exhaust-pump by reversing the taps $G$ and $H$, which remain in the position shown, and the remaining liquid air is drawn off again through $Q$, which is then closed. The valve $M$ is now opened by turning the spindle controlled by the hand-wheel $\mathrm{N}$, and the hydrogen at about $-205^{\circ} \mathrm{C}$., issuing into the chamber $\mathrm{P}$, is cooled by free expansion through, say, $10^{\circ}$, to $-215^{\circ} \mathrm{C}$., and then returns by the passage $L$ and the pipe $O$ to the gasholder. But before doing so it begins the process of intensification by passing over the coil $\mathrm{K}$ and giving up to this coil and the high-pressure hydrogen within it the ten degrees of No. I 656, VOL. 64] 
additional cooling below $-205^{\circ} \mathrm{C}$. which it had gained by expansion. Thus the high-pressure gas which succeeds it reaches the expansion-valve at $-215^{\circ} \mathrm{C}$., and expanding from a lower temperature gains by free expansion a greater amount of cooling, say $15^{\circ}$, so that it now passes away over the coil at $-230^{\circ} \mathrm{C}$. and cools to this temperature the compressed gas by which it is succeeded. This intensification proceeds until the cooling reaches the boiling point of hydrogen at the pressure obtaining in $P$. That pressure is practically atmospheric, since the vessel communicates with the gasholder, which is sealed by a few inches of water. Liquid hydrogen then collects in the lower part of the vessel P.

One of the results of liquefying hydrogen has been to show that helium is a still more volatile gas. It is possible, therefore, to reach a lower temperature than that of liquid-probably even than that of solid-hydrogen by applying to helium the same process of free expansion with intensification by counter-current interchange which has succeeded in liquefying hydrogen. But helium is an exceedingly rare gas, so that the cost of further advances will be very great. Moreover, the most volatile gas probably becomes solid and loses practically all vapourtension at a temperature above the absolute zero, so that for the attainment of that interesting point no combination of the three methods of cooling above described will suffice. Some fourth system of pumping energy will have to be devised before any portion of matter can be absolutely deprived of heat, and it is for the discovery of this fourth method that onlookers interested in low temperature research are now waiting.

\section{PROFESSOR TAIT.}

$\mathrm{I}$ the month of February, Prof. Tait, owing to a lingering illness, resigned the chair of natural philosophy in the University of Edinburgh. Since then the graver symptoms of his illness had somewhat abated, and it was hoped that he might live to enjoy some years of rest and relaxation.

This hope was disappointed by his sudden death on july 4, at Challenger Lodge, Wardie, whither he had been removed for change of air on the invitation of his friend and former pupil, Sir John Murray.

The end of his blameless life and brilliant career brings to many an irreparable gap in their circle of friendship, and to the University of Edinburgh the loss of her chief ornament. Of late years Tait had confined himself more and more to his class work, to the management of the affairs of the Royal Society of Edinburgh, and to the pursuit of his manifold scientific investigations. But, although his direct participation in University affairs diminished, his colleagues never lost the impression that a great man dwelt among them, and not one of them would have dreamed of taking action in a matter likely to interest Tait without considering his opinion. To those who knew him intimately, and therefore loved him, the coming years will never fill his place, although they may alleviate the sense of loss by weaving around it happy memories of flashes of his keen and rapid intellect, of the merry geniality and quaint eccentricity of his singularly beautiful character, and of his staunch, almost quixotic, devotion to an approved cause or to a friend.

Tait was in most senses an Edinburgh man. He was born at Dalkeith on April 28, 1831. His early education was obtained at the Dalkeith Grammar School, and at the Circus Place School in Edinburgh. Like his namesake, the late Archbishop of Canterbury, Tait was a distinguished pupil of the Edinburgh Academy ; and loved to tell amusing stories of his mathematical master, Dr. Gloag, whose stern, eccentric character was one of his favourite recollections. At the University he studied for a session under Kelland and Forbes. The former became his colleague and lifelong friend, and he cherished the memory of the latter even in such insignificant matters as the details of class-certificates and class-examinations; and, when the priority or credit of Forbes's work was called in question, he defended him with a ferocious knight-errantry that,surprised those who knew Tait little and seemed so characteristic and charming to those who knew him well.

Some of Tait's Academy schoolfellows are still alive, and they speak of him with a mixture of love and respect which shows that he must have been a leading figure among them. Clerk-Maxwell was his most intimate school and college friend, and the friendship thus begun continued to the end of Maxwell's life, absolutely undisturbed by the fact that the two were rival competitors for the Edinburgh chair in 1860 . The two men were in truth the Damon and Pythias of British science. Each in his special way was strong in mathematics, both had intense love for physical science, and both were men of wide and varied culture. Each understood perfectly both the strong and the weak points of the other, and both were men of playful disposition and of absolute frankness and sincerity. Those who have occasionally seen letters that passed between them will readily agree that their correspondence should be preserved with a view to ultimate publication; for it would undoubtedly prove one of the most interesting scientific documents of the nineteenth century.

The promise of the two illustrious Edinburgh friends was amply fulfilled in Cambridge. Tait was senior wran gler and first Smith's Prizeman in 1852, being then twentyone years of age, and Maxwell was second wrangler and first Smith's Prizeman, equal with Routh, in 1854 . They were happy in their private tutor, William Hopkins, of whom Tait always spoke with the highest appreciation, and to whose tuition he attributed with characteristic generosity much of the mathematical skill which doubtless came to him by the grace of God. He often contrasted the method and spirit of Hopkıns' teaching with the work of the modern coach ; but in his depreciation of the latter he perhaps scarcely allowed enough for the brilliancy of Hopkins' pupil and the altered circumstances of the tutor of to-day.

Into the boisterous joviality of Cambridge undergraduate life in his time Tait entered fully, and one often envied the boyish zest with which in middle age he would recall the part he had taken in many a college prank at Peterhouse in his youth. He was, indeed, all his days a sympathiser with the frolics and the foibles of ordinary men, and his stately figure and the genial smile on his rugged, manly face will be as much missed on the green at St. Andrews and in the smoking room of the "Royal and Ancient" as it will be in the quadrangle of the University. Tait was a keen golfer, and for forty years his invariable recreation was an annual holiday at St. Andrews, which he spent mainly on the links. $\mathrm{He}$ watched with great delight the triumphal progress to the championship of his amiable son Freddy, and it was said, probably with truth, that Freddy's fame was dearer to him than his own scientific renown. There is little doubt that Freddy's untimely death in the South African war and the agonising weeks of suspense that preceded the final news of his fate hastened the onset ot his father's last illness, and it is certain that it darkened the close of a singularly placid and happy life.

In 1854 Tait was appointed professor of mathematics in the Queen's College, Belfast, and there he became acquainted with Andrews the chemist, and through him with Rowan Hamilton the mathematician. These two men exercised a decisive influence on his future life, and, as was his way, he repaid them both with the tenderest regard and reverence. Andrews stimulated his love for well-directed physical research, and helped him to cultivate that marvellous power of clearly apprehending and plainly

NO. I 656 , VOL. 64] 